72 patients $(77.4 \%)$ were managed in non-critical care settings [mean age 72.7 yrs (28-99)]. 48.6\% (35) survived to discharge, $14.3 \%$ (5) required LTOT and $5.7 \%$ (2) died within 30 days of discharge. Flow rates ranged $20-65 \mathrm{~L} / \mathrm{min}$. In non-ICU patients, survival was negatively correlated with increasing flow rates $(\mathrm{r}=-0.86$ ). Patients requiring $\geq 60 \mathrm{~L} / \mathrm{min}$ had an $86 \%$ mortality rate $(\mathrm{p}=0.0001)$.

Conclusion Mortality rates were higher in patients managed on NHF in a non-critical care setting. A negative correlation was present between flow rates and survival outside of ICU. This may be explained by an older patient cohort, associated comorbidities and premorbid performance status. However this information could help guide clinical decision making in acutely unwell patients with limited escalation options.

\section{P189 OXYGEN USE IS BECOMING MORE CONSERVATIVE ON INTENSIVE CARE UNITS IN THE UK}

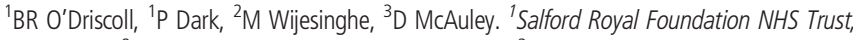
Salford, UK; ${ }^{2}$ Royal Cornwall Hospitals Tust, Truro, UK; ${ }^{3}$ Royal Victoria Hospital, Belfast, UK

\subsection{6/thoraxinl-2016-209333.332}

Background There is controversy about the optimal level of oxygenation for patients in intensive care units (ICU) and several recent publications have raised the possibility of harm from hyperoxaemia amongst ICU patients. ${ }^{1}$ Most recent ICU publications have reported that hyperoxaemia is common. The aim of this project was to audit blood gas data at two hospitals to determine if there is evidence of changing practice in recent years.

Methods We audited all available ICU blood gas datasets for Hospital A for $2005(\mathrm{n}=16,734), 2010(\mathrm{n}=12,714)$ and 2015 $(\mathrm{n}=17,292)$ and data from Hospital B from 2012-2013 ( $\mathrm{n}=11,006)$ and for $2015(\mathrm{n}=22,223)$.

Results At Hospital A, the percent of ICU blood gas samples with hyperoxaemia $\left(\mathrm{SaO}_{2}>98 \%\right)$ fell from $57.4 \%$ in 2005 to $45.1 \%$ in 2010 and 29.0\% in 2015. Mean $\mathrm{SaO}_{2}$ fell from 97\% in 2005 to $96 \%$ in 2015 . The mean $\mathrm{PaO}_{2}$ also fell from $15.1 \mathrm{KpA}$ in 2005 to 13.5 in 2015 (The reference range for $\mathrm{PaO} 2$ is 12.0 to $15.0 \mathrm{kPa}$ ). Samples from hospital B did not span such a wide time range but they demonstrated a similar fall in the proportion of hyperoxaemic samples from $42.7 \%$ in $2012-2013$ to $29.7 \%$ in 2015 which was very similar to the data for Hospital A in 2010 and 2015 (45.1\% and 29.0\%).

Conclusions There is evidence from two hospitals that the use of oxygen in Intensive Care Units has become more conservative in recent years, possibly as a result of recent publications which have identified poor outcomes in association with hyperoxaemia. A wider survey will be undertaken to determine if this trend is taking place in Intensive Care Units throughout the UK.

\begin{tabular}{|c|c|c|c|c|}
\hline $\begin{array}{l}\text { Oxygen } \\
\text { saturation } \\
\mathrm{SaO2} \\
\text { ranges }\end{array}$ & $\begin{array}{l}2005 \\
\text { Percent of } \\
\text { Hospital A ICU } \\
\text { blood gas } \\
\text { samples }\end{array}$ & $\begin{array}{l}2010 \\
\text { Percent of } \\
\text { Hospital A ICU } \\
\text { blood gas } \\
\text { samples }\end{array}$ & $\begin{array}{l}2015 \\
\text { Percent of } \\
\text { Hospital A ICU } \\
\text { blood gas } \\
\text { samples }\end{array}$ & $\begin{array}{l}2015 \\
\text { Percent of } \\
\text { Hospital B ICU } \\
\text { blood gas } \\
\text { samples }\end{array}$ \\
\hline$<70 \%$ & $0.7 \%$ & $0.7 \%$ & $1.4 \%$ & $2.9 \%$ \\
\hline $70-89.9 \%$ & $1.7 \%$ & $3.7 \%$ & $3.7 \%$ & $6.1 \%$ \\
\hline $90-94 \%$ & $4.0 \%$ & $7.8 \%$ & $10.2 \%$ & $12.8 \%$ \\
\hline $94.1-98 \%$ & $36.3 \%$ & $42.7 \%$ & $55.6 \%$ & $48.5 \%$ \\
\hline$>98 \%$ & $57.4 \%$ & $45.1 \%$ & $29.0 \%$ & $29.7 \%$ \\
\hline
\end{tabular}

\section{REFERENCE}

1 Helmerhorst et al. Crit Care Med 2015:43:1508-19.

\section{P190 CHARACTERISTICS AND OUTCOME OF PATIENTS WITH ACTIVE TUBERCULOSIS REQUIRING INTENSIVE CARE ADMISSION, 2010-2015}

NM Shah, S Patel, K Myall, H Milburn, RA Breen. Guy's and St. Thomas' NHS Foundation Trust, London, UK

\subsection{6/thoraxjnl-2016-209333.333}

Introduction Severe tuberculosis (TB) infection requiring admission to the intensive care unit (ICU) has been reported to be associated with a poor prognosis; however, no data on this cohort of patients from the UK is available. We sought to characterise and report the outcome of this patient group, looking to identify prognostic markers of a poor outcome.

Methods All patients admitted to the ICU at our London tertiary referral centre between $01 / 01 / 10$ and $31 / 12 / 15$ and coded as having $\mathrm{TB}$ were identified and cross-referenced against the London TB register.

Results 29 patients were identified which represents 4\% (29/790) of all TB notified at our centre in the study period. Median age was 41 years (22-86); 72\% were male. 69\% had pulmonary TB; 24\% were HIV-infected, with a median CD4 count on admission of 134/uL (17-277). 14\% were AFB smear-positive; 79\% had culture-positive TB and $86 \%$ grew fully-sensitive organisms. The most frequent indications for ICU admission were hypoxic respiratory failure (38\%), haemodynamic compromise (24\%) and hypercapnic respiratory failure (21\%). Median A-a gradient was $12.9 \mathrm{kPa}$, median $\mathrm{PaO}_{2} / \mathrm{FiO}_{2}$ ratio was $29.9 \mathrm{kPa}$. $72 \%$ required mechanical ventilation (median ventilation days 8.4). Two patients received extracorporeal membrane oxygenation therapy for severe respiratory failure. Median APACHE II score was 16 and median SOFA score was 4. Median length of stay in ICU was 7 days and in hospital was 24. At 30 days, 35\% remained inpatients (of which 14\% remained in ICU), 59\% had been discharged home and 21\% had died.

Table 1 summarises the differences between survivors and those who died.

Abstract P190 Table 1 Patient characteristics comparing median values in the patients who survived to 30 days, against those who died. Values are displayed as median (range).

\begin{tabular}{lll}
\hline & $\begin{array}{l}\text { Survived } \\
(\mathbf{n}=23)\end{array}$ & $\begin{array}{l}\text { Died } \\
(\mathbf{n}=6)\end{array}$ \\
\hline Age (years) & $41(22-79)$ & $58(37-86)$ \\
ICU Length of stay (days) & $7(2-54)$ & $11(3-64)$ \\
Hospital Length of stay (days) & $22(5-228)$ & $44(8-66)$ \\
CRP (mg/L) & $71(0-303)$ & $104(58-232)$ \\
White cell count (x10^9) & $9.1(3.2-29.9)$ & $11(3.3-21.3)$ \\
Haemoglobin (g/L) & $94(71-156)$ & $88(75-111)$ \\
Albumin (g/L) & $27(15-44)$ & $21(17-27)$ \\
pH (on admission) & $7.38(7.04-7.47)$ & $7.30(7.14-7.59)$ \\
p02 (kPa) & $10.53(6.9-40.0)$ & $9.12(7.0-10.6)$ \\
pC02 (kPa) & $5.92(3.3-14.6)$ & $9.03(4.2-12.1)$ \\
P/f ratio & $32(13.2-60.3)$ & $25.2(12.2-30.3)$ \\
Ventilator days & $2(0-47)$ & $6(2-56)$ \\
Days on cardiovascular support & $0(0-13)$ & $3(0-56)$ \\
Days on renal replacement therapy & $0(0-19)$ & $5.5(0-15)$ \\
\hline
\end{tabular}

